\title{
The Dynamics of Public Participation in New Technology Transitions: The Case of Dockless Bicycle Hire in Manchester
}

\author{
Geoffrey Dudley, David Banister, and Tim Schwanen
}

\begin{abstract}
New technologies are playing an increasingly important part in shaping the development of city transport and the wider built environment. Relatively little attention has, however, been given to how the technologies evolve in social and political terms, so that the public are not just seen as the passive receivers of new technology. Technological transitions are not only about the technology, but also about the social and political implications of innovation and how people respond to the new mobility. Participatory exchange and the policy process are essential parts of that approach. This paper explores the dynamics of how a technological innovation failed as a niche-innovation in terms of the socio-technical transitions framework. It uses the case study of the Mobike dockless bicycle hire scheme in Manchester to illustrate the reasons for failure. These included poor participatory practice in the earlier stages of the scheme, together with the inability of the innovator to respond appropriately through participatory exchange, including the direct participation of the public through the technology, in the implementation stage.
\end{abstract}

\section{Disruptive Innovations and the Paradox of Public Participation}

The essence of innovation lies in its ability to bring novelty and unpredictability to behaviours, and also seemingly established patterns of thinking. To an innovator, particularly in the case of a technological innovation operating in a competitive market, speed in acting can be the priority to gain advantage over other innovators, and to win a share of the market that results in financial viability. However, there can also be an innate tension between the power of the public as consumers of the innovation, and as citizens participating in a consultation process that considers the wider questions of public need. As consumers, the public can possess significant power, and thus cause the key paradox that, in placing predominant emphasis on seeking market share, the innovator may be unaware of the diversity of the market, and the local conditions. Consequently, if the innovator places too much focus on the technology of the innovation itself, then other essential elements, including strategy, business plans, marketing, and organisation can be overlooked in the anxiety to place the innovation on the market as fast as possible (Schneider, 2017, 78).

Spontaneous technological innovation has become more evident in recent years, particularly in the case of transport. This can be illustrated with examples such as ride-hailing and dockless bicycle sharing, where innovators are primarily concerned with obtaining investment capital so that they can gain market dominance, even though the innovation may be highly subsidised. After market share is achieved, the prices charged can be raised so that profits are made. This is classic rent seeking strategy with the aim of obtaining local monopoly control. Perhaps the prime example of this method has been the ride-hailing app Uber, which expanded rapidly worldwide while continuing to make losses (Dudley et al, 2017). 
The argument being put forward in this paper is that technological innovation in transport cannot be successfully implemented without a participation process, which can counter-balance the aims of the innovator to flood the market rapidly. These aims follow the tendency to work on the premise that people want innovation, and that after it has gained a dominant market position an innovation can subsequently be modified or extended, and prices raised so that profits are made. In terms of consultation this would result in minimum notice, limited collaboration with the local authority, and little concern over local factors. There would be no effective participation process, as defined by Rowe and Frewer (2005), or Cornwall (2008). In Arnstein's (1969) terms there would be total non-participation.

However, it can be said that participation in the scenario just described is limited to only the decision making processes, whereas direct public involvement in the process of innovation will occur only after implementation, and not before. Such an approach to participation means that the public holds significant power, and places the onus on the innovator to react in a way that allows the innovation to be carried forward. As Cornwall observes, participatory interventions may result in effects that were never envisaged at the outset (Cornwall, 2008, 274). Consequently, much depends on how people take up and make use of what is on offer, as well as on supportive processes that can help build capacity, nurture voice, and enable people to empower themselves (Cornwall, 2008, 275).

This process of public involvement is dynamic, and its resolution determines the success or failure of any disruptive innovation, such as that described in this paper. Christensen (1997) describes the situation where a new product takes root initially in simple applications at the low end of the market, and then relentlessly moves up the market, eventually displacing established competitors. In elaborating the dynamics of these change processes, although the technological innovation in itself may be disruptive through its novelty, it is the reaction to it by the public that is the more important disruptive force. Thus 'low end disruption' (Christensen, 1997, 23) may offer an innovation to a wider range of people than previously served, but it is the reaction of this public that will determine the intensity and the trajectory of the disruptive force. Equally, if the innovator fails to respond in a constructive way to this means of participation, then the innovation can fail. After implementation, it is therefore the public that can become the disruptive force, rather than the innovator or the innovation itself.

As Christensen et al (2015) acknowledge, the qualification 'disruptive innovation' is misleading when it is used to refer to a product or service at one fixed point, rather than to the evolution of that product or service over time. Thus, in order to be able to become a successful 'new market disruption' that targets customers who have needs that were previously unserved by existing incumbents (Christensen, 1997, 23), an innovation can require a network of support that is integrally connected to partnership through participatory exchange. The dynamics of these processes, and the often complex interactions involved, highlight the need to understand how users frame their needs and expectations. Otherwise, participation can become co-opted for managerialist and justificationalist ends (Chilvers, 2009, 412). As Tritter and McCallum (2006) observe, a linear hierarchical model of involvement, such as Arnstein's ladder of participation (1969), fails to capture the dynamic and evolutionary nature of user involvement. They argue that a more appropriate approach 
must recognise the multiple sources of potential user power and the dependence of decision makers on user support, and redraw the context within which conflict over the ability to influence decisions occurs (Tritter and McCallum, 2006, 165).

This paper follows the case study of a failed dockless bicycle hiring scheme in Manchester. This presents a means to examine participation as exchange in the form of a direct mechanism of engagement with the shaping of cities, through a widely accessible scheme, that apparently offered the potential to significantly shift transport demand, but where the innovator failed to both prepare the ground, and to respond to public need. The case therefore represents a different type of 'participatory exchange' between planning actors that is (at least partly) material and performed, in contrast to the more usual emphasis in participation on oral communication and deliberation in relation to decision making.

\section{The Dynamics of Dockless Bicycle Hire}

\section{a. The Business Model}

Until 2014, when dockless bicycle hire companies began to operate, bicycle hiring schemes generally involved the bicycle being physically docked and locked in docking stations at appointed places. Over the last twenty years, this type of bike sharing has become more popular, given the convenience and the cost offered as an alternative to personal bicycle ownership. Consequently, the numbers of cities offering bike share increased rapidly from just a handful in the late 1990s, to over 800 by 2016 (Fishman, 2016). Given the fixed docking stations, the distance one lives from a station is an important predictor for bike share membership, with commuting the most common trip purpose for annual members (Fishman, 2016). Until recent years, these docked systems generally had a more advanced uptake in Europe, with notable systems acting as sources of learning, and inspiring the creation of new systems (Parkes et al, 2013).

Bicycle hiring in itself was not a new idea, but its spread in the twenty first century reflects a greater exploration of the commercial possibilities, combined with a more intense search to tackle traffic congestion and environmental problems by finding viable alternatives to motor vehicle use (see Shaheen et al, 2010, 2011). The spread of bike sharing can therefore be dependent on institutional and personal learning. We have noted that this study examines a type of direct participatory exchange that is material and performed, rather than depending on oral communication and deliberation, and this distinctive type of exchange can be enhanced if local conditions are amenable to an understanding and sympathy for what the public is communicating. In this context, Schwanen (2016) argues that successful innovation depends not only on institutional embeddedness, but also on socio-spatial embeddedness. Thus he emphasises that radical innovations are more likely to emerge and flourish in places offering 'institutional thickness,' defined as a localised capacity to support innovation resulting from formal and informal institutions, such as grant schemes or knowledge brokers funded by local government, as well as place-specific cultural norms, values, worldviews and networks. However, we will see in the case study that the dockless bicycle hiring company, Mobike, is a globalised concern that in Manchester made little attempt to respond to local conditions, and where communication broke down with the public authorities, despite initially being 
welcomed. Institutional thickness in terms of a sympathetic local environment is not necessarily enough for an innovation to take root. As Schwanen comments with regard to bike sharing, cities cannot be heralded as actors who can bring about significant change unilaterally. This is to deny both the social, political, cultural, technological, and other struggles that characterise cities, and the critically important role that national and supranational actors play in shaping their innovation and lowenergy transition trajectories (Schwanen, 2015, 7107). Thus we will see in the case study that, even in conditions where institutional thickness appeared to exist, a breakdown in communication and co-operation can cause a scheme to fail.

Given that docked bicycle sharing had its roots in Europe, conditions here have been relatively amenable to spreading the innovation throughout the continent. In the case of dockless bicycle hire, however, its roots are in China, so that spreading to new territories required rapid learning processes. As a variation on the more traditional bike sharing, dockless bike hire is not essentially new, but takes advantage of modern technologies to offer a more flexible and cheaper option. Typically, dockless bicycles can be tracked and locked or unlocked using a smart phone app. This means that, unlike an orthodox docked bicycle hiring system, a dockless bicycle can be collected and left at any location, although 'geo-fencing' can be adopted by an operator as a means of setting virtual geographical limits, in order to avoid bicycles being left in locations deemed undesirable. Consequently, by controlling where the bicycle is collected and left, the operator can hope to more closely supervise and control the diffusion of the bikes (Yi et al, 2018, Zhang et al, 2019).

This control of bike diffusion can be important for the viability of a dockless scheme, given the costs involved in collecting and moving the bikes. At the same time, as we will see in the Manchester case study, restricting the area of operation by means of geo-fencing can limit the usage of the bikes. Regardless of the operational area, however, the dockless technology is underpinned by significant behind the scenes labour, with the operators frequently employing third-party operators to physically reposition and maintain the bikes on the ground. It is estimated that around 10-15 people are required to be employed in order to look after 1,000 bikes, and that the workers monitoring the bikes can account for 30 per cent of total costs (Financial Times, 2017, 'Bike apps saddled with high labour costs,' $27^{\text {th }}$ December). In order to assist with bike control, the operators have generally charged a deposit, and employ a credit scheme, with penalties being imposed on those who leave the bikes in places outside the 'geo-fencing' areas and in inappropriate places (the bikes are tracked by a GPS system). Nevertheless, given the inherent character of dockless systems, they are more susceptible to theft and vandalism than the orthodox docked systems, and as we will see in the case study of Manchester, this has emerged as a major problem in some locations for the dockless operators.

From its outset in China, dockless bike hire has been subject to intense competition, with a number of operators becoming insolvent, including Wukong Bicycle and Go Bee. From this competition, two companies, Mobike and ofo, have emerged as the principal players. Ofo was launched in 2014, and Mobike in 2015, and both have received substantial investment, principally from the Chinese equity companies Tencent and Alibaba, respectively. For example, by the time Mobike launched its first scheme outside Asia in Manchester in 2017, the company had raised more than US $\$ 400$ million dollars from investors in just over a year. However, given the intense 
competition in their home base, both Mobike and ofo have adopted strategies of expanding at a rapid rate by offering subsidised rides, with the result that they have been making heavy losses (in general, a dockless bike requires three hires per day to break even, even though the life of the bike before it needs replacement also needs to be considered). By 2018, it was estimated that Mobike was losing US \$50 million per month, and ofo US \$25 million per month (Financial Times, 2018, 'Cyclical momentum as Meituan deal values Mobike at US \$3.7bn,' $5^{\text {th }}$ April). This has led to widespread criticism that the companies are not operating a sustainable model, and by 2018 ofo in particular was feeling the financial pressure. Consequently, it ceased its operations in India and Australia, and made significant cutbacks in Japan, South Korea, Singapore, and Hong Kong. In the UK, ofo ceased its operations completely in 2019.

For its part, Mobike has to some extent been cushioned financially by its takeover in 2018 by Meituan Dianping, China's largest online services company. This deal valued Mobike at around US \$3.7 billion. Nevertheless, for both Mobike and ofo, there is pressure from investors to make their business models more financially sustainable, meaning that the emphasis is now more on consolidating their presence rather than outright expansion. In 2018, Mobike operated 9 million bikes in more than 200 cities across 15 countries, and ofo operated 10 million bikes in more than 250 cities across 20 countries (although this was reduced in 2019).

As we will see in the Manchester case study, the premium placed on speed of expansion by Mobike and ofo perhaps inevitably fails to give public participation in scheme design and use a high priority. There is therefore the paradox that we noted earlier that although the companies depend on public use of the services, the business model - or seeming lack of it, precludes spending time on participatory exchange.

Nevertheless, these weaknesses should not obscure the innate potential of dockless bike hire as a technological innovation. For example, in the terms used by Christensen (1997), it could be argued that dockless bike hire is both a 'low end disruption' in offering cheaper hire than the docked operators (in the UK, the dockless charge has been typically $50 \mathrm{p}$ per half hour), and also, at least potentially, a 'new market disruption' that targets needs in terms of flexibility of use that were previously unserved by existing incumbents. The potential is indicated by one of the few evaluations of dockless bike hire (Sun, 2018) that takes Beijing as a case study. The survey found that the majority of dockless users use the bikes for their 'last mile' of travel, and that nearly half of the users always transfer to other modes of public transportation such as the metro (84 per cent), and bus (54 per cent) (Sun, 2018, 7). The convenience and price of dockless bikes therefore offers significant potential for furthering an integrated public transport system as an alternative to car use, It could nonetheless be argued that this potential in itself requires significant intervention and promotion from public authorities, and an understanding of this potential through public participation. Sun concludes that start ups such as dockless bike hire are too busy chasing territory and investment to focus on providing a good service, and that dockless bike hire as a disruptive innovator does not absolve cities from the principles of sound city planning, street design, and realising the value of public spaces (Sun, 2018, 10-13). 


\section{b. The Manchester/Salford Case Study}

The Manchester/Salford Mobike case study has been chosen because of the dilemmas it poses between the aims of a globalised innovator seeking to expand its business as quickly as possible, and a commitment to a participatory exchange with the public in a particular locality. In this case, the company failed to recognise the power as a disruptor offered by the public rather than the innovator and its innovation, and made little attempt to address this basic weakness. In fact, public participation was notable for its absence from the time Mobike launched the Manchester scheme - its first outside Asia, in June 2017, until the company made the decision to end the scheme in September 2018. In essence, Mobike basically acted unilaterally throughout this period, and also generally failed to co-ordinate its activities with the public authorities. As shown below, the company has subsequently accepted that this lack of co-ordination and participatory exchange was a mistake, although there is also an awareness that the operational prerequisites for a rapid technological innovation are not necessarily compatible with the best practice expectations of 'upstreaming' public involvement in scientific (Wilsdon and Willis, 2004) or urban development practice (RTPI, 2010).

This is not to say that Mobike was not welcomed by the local authorities in Manchester. On the contrary, in his election manifesto of 2017, the Mayor of Greater Manchester, Andy Burnham, had expressed his intentions to introduce a major bicycle hire scheme to the area. The Mayor of Greater Manchester, geographically a collection of ten local authorities in and around the city with a population of around 2.8 million, was a newly created post, and the Mayor saw the cycle hire scheme, and the promotion of cycling generally, as one of the principal means to combat longstanding motor vehicle congestion and environmental problems in the area. As part of this plan, Burnham also appointed Chris Boardman, an Olympic cycling gold medallist, as the first Greater Manchester cycling and walking commissioner. In 2017-18, Boardman produced a plan to construct major cycling infrastructure in the area. However, despite this commitment to create 'institutional thickness' for cycling in Greater Manchester, the area generally lacked a tradition of cycling promotion and development, and there was not an established governance framework to act as a counterweight to the activities of Mobike. Consequently, levels of cycling were generally low. For example, only 2 per cent of commuters in Manchester made use of a bike (Manchester Evening News, 2017, 'Lots of people say they would love to cycle to work in Greater Manchester, but even more say they wouldn't feel safe,' $14^{\text {th }}$ November). This should be compared with the UK average of 4 per cent of commuter journeys made by bicycle (National Travel Survey, 2018, 0409).

For its part, Mobike introduced the scheme on the basis of distributing 1,000 bikes in the city of Manchester, together with the neighbouring city of Salford, in an initial six-month trial to see how events developed. This followed the company's strategy in Asia to seek rapid expansion and to subsidise rides in an endeavour to establish itself in a territory at maximum speed in order to deter competition. From the outset, however, Mobike suffered from high levels of theft and vandalism of the bikes that continued throughout the scheme, and eventually became the principal stated reason for its termination. Consequently, by the end of the scheme Mobike estimated that each month ten per cent of its bikes were unavailable because of theft and vandalism. 
The major measure the company took was to reduce the geo-fencing area radically in November 2017. This meant that the bikes could now be collected and left only in central Manchester. This measure was received adversely by the public, which complained that the restrictions on the use of the bikes severely reduced their convenience and scope for use over a larger area. There was also dissatisfaction over the quality of the bikes. Initially after reducing the geo-fenced area, the company expressed the intention to commit itself to the scheme in the long-term, but in September 2018 it decided to terminate the scheme.

In essence, Mobike lacked an understanding of the desires and needs of customers, and relied excessively on the attraction of the innovative dockless technology itself. No significant market research or consultation took place prior to the scheme, and the planning of the scheme was minimal. It was public reaction rather than the innovation itself that made it disruptive, and the lack of intervention by the public authorities did nothing to ameliorate the situation. In this context, the framework of socio-technical transitions can provide a valuable means of understanding better how an innovation can fail to take root.

\section{The Dynamics of Disruptive Innovations as Failed Niche-Innovations}

For Mobike in Manchester, public participation was by-passed in favour of acting unilaterally and at speed to implement its scheme. The priority was to establish market share, even at the price of operating at a loss. The cost of entry was low, basically involving the cost of the bikes. For their part, the local authorities welcomed in Mobike, as the scheme came at zero public expenditure, and Mobike was able to bypass the usual regulatory constraints. Mobike therefore operated independently of other transport services, and assumed that the market would be there for the 1,000 bikes they introduced to Manchester/Salford.

In order to understand better the dynamics of Mobike's failures in planning and public engagement, we can outline briefly how the transitions concept of niches as protective spaces can provide a framework for analysing the limitations of the Mobike approach over time. In this context, the socio-technical approach to transitions highlights coevolution and multi-dimensional interactions between industry, technology, markets, policy, culture and civil society. The multi-level perspective (MLP) on socio-technical transitions addresses the co-evolution of these elements (Geels and Kemp, 2012, 50-1, original emphasis). The basic premise of the MLP is that transitions are non-linear processes that result from the interplay of multiple developments at three analytical levels: niches (the locus of radical innovations), socio-technical regimes (the locus of established practices and associated rules), and an exogenous socio-technical landscape (Geels and Kemp, 2012, 52).

The MLP provides a longitudinal perspective on the dynamics of stability and change, but in this paper we are focusing on niches, and in particular how a technological innovation - a new technology, social practice, or special government intervention may fail to advance because it is not able to attain the status of a niche-innovation. Niches are particular domains of use, actor constellations and geographical areas with special characteristics. Crucially, what happens in the niche is shaped by external developments. For example, the use of bicycles or electric cars is shaped by the road infrastructure, priority rules, fiscal measures, climate change concerns and the 
economics of using other means of transport. These developments not only shape the willingness of individuals to engage in the use of a bicycle or electric car, but also shape the expectations and strategies of companies and government (Geels and Kemp, 2012, 53).

Thus niches are 'protected spaces' such as research and development laboratories, subsidised demonstration projects, or small market niches, where users have special demands, and are willing to support emerging innovations (Geels and Kemp, 2012, 52-3). Initial protection is deemed essential, because path-breaking innovations usually cannot compete successfully within selection environments embodied in incumbent socio-technical regimes. Hence, the protective space is needed to shield the innovation against (some of) the prevailing selection pressures. Within the protective space, niche actors can nurture the path-breaking innovation so it becomes more robust through performance improvements and expansions in supportive sociotechnical networks (Smith and Raven, 2012, 1025).

The concept of a niche is important for the study of Mobike in Manchester/Salford because, if an innovation of this type fails to find the necessary protection to become a niche-innovation, then it is unlikely to become established in the mainstream in due course. It is therefore important to distinguish between Mobike as an innovation (i.e. a dockless bike sharing scheme) and Mobike as actor, which failed to construct the network of local support necessary to become a successful niche-innovation.

Protective space therefore entails more than external research and market support to shield the innovation from selection pressures. In addition, it requires the innovator itself to take positive action in terms of market and business plans that can prepare the ground locally for the innovation and provide the means to act proactively in response to changes in market conditions.

It is also important to note that power and politics are keys to an innovation's pathway, and need to be considered (see Geels, 2014, 2018). In this context, Smith and Raven (2012) provide important insights into how an innovator may succeed, or fail, in creating a niche by identifying the three elements of shielding, nurturing, and empowering as being necessary for the essential protective space to form around an innovation (Smith and Raven, 2012, 1025-6). One of the key means to obtain niche empowerment is through the construction of narratives, whereby actors strategically re-tell the past to make new sense of the present, and envision alternative futures (Smith and Raven, 2012, 1037).

In the case of Mobike, one of its key failures was to construct an effective narrative that could give the public a vision of dockless bike hire providing a means to a more efficient and environmentally friendly built environment in the future. In order to organise these processes of shielding, nurturing, and empowering through the construction of narratives, then a process of strategic niche management is required to bring this about. Lovell (2007) describes how governments and other actors can foster the introduction of new technologies by establishing or facilitating experiments within protected niches. Lovell argues that, in order to manage a niche successfully, firstly, due regard should be given to the messiness of socio-technical change, secondly, the politics of socio-technical system change need to be considered in considerable depth, and thirdly, allowance needs to be made for non-governmental actors taking a lead role (Lovell, 2007, 35-42). Strategically managing a niche-innovation therefore 
requires articulation of expectations and visions, building of social networks, and learning processes (Geels et al, 2018, 26-7). An innovation such as Mobike, therefore, cannot become a niche-innovation purely by its own actions, important as these are. Instead, it requires a more co-ordinated and multi-actor approach over time.

If a strategic approach is required to form a niche-innovation then, as happened in the case of Mobike, it is important to understand better how the dynamics of innovations may fail to create the protective spaces necessary to form a niche-innovation. The case study will therefore examine how Mobike in Manchester/Salford failed to construct any system of public engagement through planning and market research, and so was unable to gain the support of policy makers and the local population. It was shortcomings in these areas, more than shielding and nurturing on the part of bodies such as the public authorities, that caused the innovation to fail. In analysing these failures, we will consider whether a different way of engaging key actors by the company would have created more effective buy-in, and thus formed a network of support around the innovation in the Manchester/Salford case.

\section{Case Study and Methods}

The case study of Manchester was selected for the principal reason that it represented an innovation moving into new territory and seeking to quickly establish and consolidate its presence. Thus Manchester was the first venture outside Asia for the major Chinese operator Mobike. For their part, the Mobike venture was welcomed in by the public authorities, and there was initial public sympathy for the scheme. Nevertheless, within fifteen months the scheme was terminated. The case study therefore offers a good opportunity to examine how a technological innovation, with important implications for the built environment, can experience a breakdown in its operational viability in both public and financial terms. This can therefore enable an examination of the dynamics of a failed niche-innovation in terms of the sociotechnical framework.

The study identified and examined relevant official and group publications, together with key secondary sources, including all published material on dockless bicycle hire for the Financial Times, The Guardian, and the practitioner journal Local Transport Today. In addition, all the online dockless bicycle hire material was studied for the local daily newspaper the Manchester Evening News. Particular attention was given to examining the evolution of the Mobike company strategy in order to gain a better understanding of the dynamics of the Manchester scheme. This data helped to understand the character of dockless bicycle hire as a distinctive technological innovation in the UK, and the implications for the operation of the Manchester scheme.

In order to gain an understanding of the underlying dynamics that determined the trajectory of the Manchester scheme, four interviews were conducted with major stakeholders integrally involved in the case study. The four interviewees here represent the innovator (Mobike), the public authorities (Transport for Greater Manchester), the system (a design engineer), and a pressure group (a cycling campaigning group). The interviews were semi-structured, not only to give interviewees the opportunity to expand on aspects which seemed important to them, 
but also to place their experience in a wider personal, institutional, and narrative context. As researchers we had no material interest in, or connection with, the case study, and sought to ensure distance from the actors concerned by analysing their evidence at all times within the context of the analytical framework adopted for the article. Each of the interviews was transcribed, and the transcriptions were then analysed to identify the material that would enhance our understanding of transition processes.

The interviews offer key insights into the distinctive perspectives of the actors involved, together with an understanding of experiences and reflective commentary on how the scheme evolved, and the thinking behind key decisions, as well as post hoc reflections on activities. This provides an important set of data for tracing the distinctive dynamics of the Mobike scheme, and the underlying motivations and reasoning behind it. The chief weakness, as ever in such case study work (Yin, 2003) is that the interview data from key actors inevitably provides a partial perspective on the story. We strive, however, to critically appraise these accounts, triangulating them for accuracy with other material on the case (Sherriff et al, 2018), in order to examine the dynamics of a failed niche-innovation. Consequently, we recount the prominent narratives seen in the case, across several stages, using illustrative quotations, and drawing out lessons with regard to the nature of public involvement.

\section{The Mobike Manchester/Salford Case Study}

The account of the case study is divided into three parts, in each of which distinctive key themes emerge. Overall, the account foregrounds how dockless bikes in Manchester/Salford failed to become a niche-innovation both because of failures by Mobike itself to prepare the way for the scheme, and then to respond to the material and performed participatory exchange with the public after implementation, and also a lack of action by the public authorities to both monitor the scheme, and to place it in the context of wider transport strategies.

The first stage of the account deals with the inception of the scheme, where the perspectives of the main actors precluded any significant public engagement. For its part, Mobike as a globalised company had a strategy of expanding the market at maximum speed, while the local authorities were happy to give the company freedom to operate, given Mobike's lack of demands on the public purse. Consequently, operational power was assumed by Mobike, but this came without the will to either provide its own operational strategy, or to seek external help in constructing a nicheinnovation.

The second section describes the operation of the scheme over a period of fifteen months. Here, the lack of detailed planning led to the scheme developing in an ad hoc fashion, while the failure of Mobike to communicate with the local authorities prevented any consideration of alternative strategies. In this case, we will see that the decision by Mobike to restrict the geo-fencing area indicated that the company was giving greater attention to the short-term financial viability of the scheme, and took insufficient account of the adverse public reaction. Together with theft and vandalism of the bikes, it meant that the public disrupted the innovation, but there was no commensurate operational strategy that allowed for this public engagement. 
The third section describes the termination of the scheme. Theft and vandalism of the bikes was given as the ostensible reason for Mobike leaving Manchester, but other factors were also at work. Mobike had now amended its strategy to give greater emphasis to commercial viability, and the company wanted to examine opportunities in other areas with greater potential for profit. For their part, the local authorities had become disillusioned with the Mobike approach, and were keen to explore new avenues. This strategy tied in with their plans to develop cycling infrastructure in Greater Manchester. Just as the perspectives of both the company and the local authorities led to the introduction of the scheme without significant public engagement, so its termination reflected the evolution of both parties' strategies. In doing so, it indicated that the dynamics of the interpretation of scheme meanings can produce a power vacuum in terms of public engagement, and inhibit the development of a niche-innovation.

\section{a. The Mobike Strategy - June 2017}

The Mobike scheme was initially welcomed into Greater Manchester by the public authorities. These included the Mayor, the Greater Manchester Combined Authority, the cycling and walking commissioner, and the executive body Transport for Greater Manchester. As we have seen, there was a political momentum to increase investment in cycling infrastructure and to promote its use, but there was not an official promotion of cycling in Greater Manchester that could have provided the necessary external support essential to the creation of a protected space for Mobike, and as we indicated earlier, this was reflected in cycling use. The dominance of the private motor vehicle was indicated in the finding by the National Infrastructure Commission that the average speed of vehicles in the city was $15 \mathrm{mph}$, the slowest in the UK outside London (National Infrastructure Commission, 2018).

Nevertheless, there was evidence that bicycle sharing offered a potential to promote the use of integrated transport in the city. Thus a survey about bike sharing in Greater Manchester (Sherriff et al, 2018) found that most of the sample would like to cycle more than they did, with the benefits of bike sharing including spontaneity, the potential to combine it with public transport, and being able to cycle in a town or city other than the one they lived in (Sherriff et al, 2018, 29). When respondents were asked about the modes of transport that were either combined with, or replaced by, bike sharing, walking was the most prominent, followed by public transport, and then private car use. The report concluded that these responses implied the potential for bike sharing to be useful for 'first mile' and 'last mile' journeys provided at public transport interchanges (Sherriff et al, 2018, 30). However, the provision of 'first mile' and 'last mile' transport by bike sharing implied a degree of co-ordination with public transport services that was not evident in the case of the Mobike Manchester scheme.

*** Figure 1 Around here please

One of the advantages for the Mobike scheme was that it did not face any significant competition from a docked scheme in Greater Manchester. In fact, the Mayor, the Greater Manchester Combined Authority, and Transport for Greater Manchester had been planning for a docked scheme prior to being contacted by Mobike. As an officer at Transport for Greater Manchester explains, a major attraction of the Mobike scheme was the lack of cost to the public authorities: 
"We were in the middle of providing a traditional docked bike solution, and had got as far as a feasibility study. We were engaging with suppliers, and planning to put things out for tender, but then Mobike got in touch. It was quite exciting, and had got the 'get up and go' atmosphere. Mobike had a good reputation, and it would be a European first in dockless bike share. With our original scheme, we were looking at things that were going to cost us a few million pounds in operational expenditure, and Mobike were offering their scheme for free, so as an authority we said, let's give it a year and see what happens. If it doesn't work out we can go back to where we were and carry on. We were looking at 'new mobility,' and trying out new things."

(Interviewee, Transport for Greater Manchester).

From the outset of the Mobike scheme, it appeared that the councils would be adopting a laissez-faire approach to the technological innovator. As the interviewed officer at Transport for Greater Manchester explained:

"We got in touch with Manchester City Council and Salford City Council and we agreed a memorandum of understanding, and this was the regulatory approach we took with Mobike. They would move the bikes and talk to us about key performance indicators, but because they were providing the service there was no strict enforcement of it. It was just a document of good faith of what they were going to do."

(Interviewee, Transport for Greater Manchester).

For Mobike, the plan in Manchester was to replicate the high speed growth strategy that it had adopted in China, with little sensitivity to the local context. As explained by the Mobike representative:

"In Manchester, there was not any form of rigorous public consultation or market testing prior to launch. The business had grown very quickly in China. For a fast moving tech company the desire was to move quite quickly. With hindsight perhaps we did move too quickly. At the time it was an open door, and so we were keen to move quickly and launch. What the team from China looked at was, could the scale be replicated that we had seen there? The model in China requires high density, and this involves a large number of rides to get the network effects. Manchester was an investment, but there was not a clear window that saw where profitability or break even would occur. It was a question that we had this service, so let's see how it goes. It was a very high growth phase for Mobike, and launching in numbers of cities was the key measure of success."

\section{(Interviewee, Mobike).}

The growth strategy used in Manchester was contrasted with the current business model used internationally by Mobike. The new strategy is 'slower':

"Where we are today is we have slowed down the launch in cities. We now focus on getting those cities to break even or move into profitability. We have launched in 22 
markets in Europe, but that's when we decided to stop the expansion and work at establishing profitable operations."

(Interviewee, Mobike).

In failing to take sufficient account of the local context, Mobike was unable to construct a power base or set of narratives around its offer, in niche-innovation protected space terms. However, the company had anticipated difficulties with public engagement and still expected it would be a break on operationalising the technology. This is indicated by the Mobike representative's comments on the merits of public consultation:

"What you have with public consultation is, on the good side, you get lots of input, but it also slows things down dramatically, and things don't get done. I'm sure if we had started consultation in Manchester in June 2017, we may still not be launched today. So as a disruptor you have to be more action orientated than consultative. That's a trade-off."

\section{(Interviewee, Mobike).}

These observations about the initial set up suggest that Mobike's strategy was based in a set of assumptions about the operation of the bike hire technology in the locality of Manchester/Salford, and procedures needed. Mobike were operating in a context where neither government support nor regulatory resistance were expected, although the political actor, the Mayor, had suggested that the particular transport mode would be welcomed in principle. The low value placed on engaging the public at an early consultative stage was due to the belief that participatory exchange would be an obstacle to launching the technology. Thus at the initial phase of the case, the localised capacities to support a niche for the innovation were mixed, and local people were excluded due to assumptions about their cultural values.

\section{b. Scheme Implementation - Fifteen Months of Operation}

The key underlying issues in scheme implementation were the innate tensions between the practices of the innovator, and public response to the details of the scheme that were produced.

Given the laissez-faire approach of the public authorities, the pricing structure was oriented towards the financial viability of the company. Within that, some assumptions were made about public acceptability of pricing structures. Mobike initially in June 2017 chose to charge a deposit of $£ 49$, which it reduced to $£ 29$ in November 2017. The bike usage itself was charged at 50p per half hour. The system of deposits was one that had been adopted in China, but was not sufficiently adapted for the Manchester context. As the interviewee from Mobike reflected, "We began to realise it is not a very price sensitive market. If people want to use a bike they will do so, and so we now generally charge something like $£ 1$ for twenty minutes. It's designed to compete with the local tram or bus use, but it's noticeable that people are less price sensitive than we thought originally." 
The pricing model in Manchester was therefore not based on detailed market research, and reflected the general lack of engagement with the values and norms of potential scheme users in the locality.

Regarding the bikes themselves, the public appeared to like the flexibility of the dockless system. This strengthened their association with the benefits of cycling, including making this mode of transport more convenient, helping users to see more of the city, improving physical and mental health, and providing a sense of freedom (Sherriff et al, 2018, 12). However, there was significant dissatisfaction with the basic quality of the machines (Sherriff et al, 2018, v). The chief weaknesses are described by a representative of a pressure group, the Greater Manchester Cycling Campaign:

"The seat post was either too high or too low for people. The bikes also didn't have gears, and so you are limited to a very slow speed. If you just go around Manchester city centre they are ideal, but for longer distances you are just stuck in first gear all the time, so it is not very comfortable."

By far the most significant problem for Mobike was theft and vandalism of the bikes. In the first month of operation over fifty bikes were vandalised or stolen, often with the lock and GPS tracker broken off, which made it difficult for Mobike to trace them (Manchester Evening News, 2017, 'Is Manchester really ready for Mobike,' $19^{\text {th }}$ July). In the first six months of operation, Mobike wrote off seventy bikes. A number of these were discovered dumped in the canal, which created a visible adverse image for the scheme (Manchester Evening News, 2017, 'Vandalism to Mobikes has forced owners to write off 70 bikes in 6 months,' $11^{\text {th }}$ December).

*** Figure 2 around here please

The issue of image was important for Mobike, with the novelty and style of the bikes set against the deficiencies of the machine, and the way they were treated by the public. The theft and vandalism continued to have a serious impact on the viability of the scheme, and was the principal reason given by Mobike for pulling out of the extension to the neighbouring town of Stockport in March 2018 after only eleven days of operation (Manchester Evening News, 2018, 'Mobike is pulling out of Stockport 11 days after launching in the town,' $23^{\text {rd }}$ March). By the time the scheme was terminated in September 2018, ten per cent of the bikes had been lost to theft and vandalism each month (Manchester Evening News, 2018, 'Manchester could be first city in the world to lose Mobikes after spate of vandalism and thefts,' $20^{\text {th }}$ August).

The persistent theft and vandalism of the bikes hindered any positive narrative Mobike might have put forward to promote the image of the scheme or engage the public with information on its potential social value. However, an alternative perspective on the causes of vandalism emerged in the interviews, which suggested the problem might not have been due to low public awareness or 'buy-in' to the scheme, but quite to the contrary indicated a potentially enthusiastic cohort of users, who were frustrated by the barriers to access that they encountered. This was neatly argued by a design engineer, who has advised Transport for Greater Manchester on bike sharing schemes: 
"It was young teenagers that were breaking the locks. You've got bikes that look like kid's bikes, but kids can't use them as they are too young to have the credit card necessary to make the payment. With a little bit of application, they could use them. Maybe if there had been an age limit of twelve we might have got away with that. If you deny someone access to something they find useful, then they are going to find ways to use them. If you have a lower age limit, it would be better."

Public subsidising of bike share for young people could have been a way to provide shielding and nurturing to the innovation. In this way, the protected space would be formed to create a niche-innovation, together with the strategic niche management necessary to carry it forward.

Indeed, reflections by the Transport for Greater Manchester interviewee suggest that such a move would have been feasible: "We subsidise young people for bus and train travel, so if we wanted to have bike share we could subsidise that as well. People under sixteen are forming their travel habits. At the moment, they are using the car as the only way to get about, but if we can combine bike share with public transport, we have a viable alternative to the car to offer them, and it can change the landscape."

Mobike's operation of the Manchester scheme was unilateral and 'top-down,' and lacked any public information strategy. As the Mobike representative put it: "We didn't invest enough in having government affairs people working in Manchester, and communication was not enough." A significant example was the decision to shrink the geo-fencing area greatly in November 2017 without any prior public awareness campaign. This meant that, from the perspective of the locality, all of a sudden bikes could only be parked in a strict 6 square $\mathrm{km}$ area within central Manchester.

The focus of decision-making on the geo-fence was narrowly instrumental, and did not expand to the sorts of niche-building work anticipated in the academic literature associated with the MLP. This is seen in the Mobike representative's reflections on the decision:

"It was very much our decision, and was designed to improve our operations. Before the restricted geo-fence, the bikes slowly became widely distributed and did not have the density required. It gets to the basic model of bike sharing. There's a size of operation that can produce a financially sustainable scheme. We have a model of so many operators per bike, which we keep commercially confidential, but if you have twenty people supervising five hundred bikes, then your model isn't sustainable. That's why we try and manage geo-fenced areas quite tightly, so that the operational costs balance income from rides."

*** Figure 3 around here please

In addition to the frustrations associated with the lack of public information, the reduction in the geo-fenced area generated dissatisfaction with the functionality of the scheme (Sherriff et al, 2018, v). Mobike's already deteriorating relationships with the locality were worsened as the public authorities had expected much greater engagement, both with the public and policy stakeholders. This is demonstrated in the comments of the officer at Transport for Greater Manchester: 
"In such things as the Mobike scheme you need a hands-on partnership, with regular meetings. One of the problems with Mobike was that there was not regular contact with Transport for Greater Manchester or the police. The relationship breaks down a bit. It was frustrating for both sides. It was hard to get hold of them, when we should have been on the same page. For example, when they reduced the geo-fencing area they didn't liaise with us. They didn't discuss their plans with us, and how we would align things with what we wanted to do. When they restricted the geo-fenced area it caught users on the hop. I think it was very counter productive."

\section{c. Termination of the Scheme - September 2018}

At the end of the six months trial in December 2017, Mobike expressed its intentions to remain in the city on a long-term basis. Nonetheless, the levels of theft and vandalism remained high, and the company was coming under increasing pressure to achieve financial viability and returns on investment. In August 2018, Mobike therefore issued what they called a 'final warning' to the 'anti-social minority' to stop stealing and vandalising the bikes in Manchester. Two weeks later the company announced its complete withdrawal from the city, and the bikes used in Manchester were dispersed to other UK cities or recycled for spare parts (Interview, Mobike representative). The final decision was a commercial one, but it centred on the negative (criminal) public response to the innovative technology, as the Mobike representative interviewed conceded: "Bike sharing requires hardware and investment in physical assets. It's not like a Facebook where there are no assets." Irrespective of the ultimate withdrawal of the scheme, Mobike claimed that the scheme had been a success, since the bikes had been used on 250,000 trips covering more than 180,000 miles (Manchester Evening News, 2018, 'Manchester first city in the world to lose bikes due to vandalism,' $4^{\text {th }}$ September).

Again a potential to build a niche was missed, as subsidising bike sharing would have assisted local planning objectives of different local actors. The Transport for Greater Manchester officer saw connections to spatial policy, for instance commenting that:

"In Manchester we've got obligations to serve the public and not just certain areas of it. We can have an area where the dockless operator wants to operate, but we want to see them go to less desirable areas, and they are not going to want to do this. If we're subsidising it then we have some sort of control. If we don't subsidise then we are just helping the operator to make money. We can use profits from where there are seven rides per day to cross-subsidise areas where there are only two or three rides per day. I don't think anyone has done that yet."

In the interviews, the coalition building work was repeatedly associated with better engagement of the public. The representative from the Greater Manchester Cycling Campaign envisioned how the connections could have been made, saying:

"We had a new Mayor, and he was looking for a public bike hire scheme. Mobike came along and said they could do it for minimum cost, but the councils need to take responsibility and not just leave it to Mobike. They need to help them with parking spaces and also advertise the service. If people know how to use the bikes better, then maybe they would use them more." 
Interviewees' reflections describe their increasing realisation of the participatory significance of the necessary infrastructure to promote cycling. The design engineer succinctly expressed this as follows:

"You can't just go around leaving objects about and not expect the local authority to take action. You have to think about the effects on other citizens. How you are going to manage it? Where are people going to go? It's just a planning process that has to be done. We have learned a lot of lessons from taking a laissez-faire approach to the planning of it in Manchester. Let's not forget it was a success in user terms. There were thousands of cycle trips that wouldn't have taken place otherwise."

This was supported by the perspective of the representative of the Greater Manchester Cycling Campaign on the cycling culture in the local context, who related the challenge of engaging people in bike hire. That representative pointed out significant challenges in respect of on-road experiences in the locality:

"How are you going to get people to use a Mobike when the roads are far too dangerous? People who cycle are those with bikes, but you want to attract people without bikes. If the roads are too dangerous, they are not going to cycle at all, even if the bikes are cheap. The reason people don't cycle is because it's not safe now. You need to enable people so that they feel safe to go out cycling, then it becomes better than being on a bus or being stuck in congestion in a car. Over the next five years you will see a radically different Greater Manchester. Perhaps then will be the time when you can have a bicycle hire scheme to complement these developments."

These findings underscore the significance of local culture in creating a niche. The perspectives of prominent stakeholders demonstrated how policy objectives and user experiences could have been bound up with action to encourage a niche for the innovation of dockless bike sharing. For instance, the construction of a protected space for cycling might have assisted in the creation of a niche for bicycle hire. A better connection between the wider narrative of infrastructure development and the niche-innovation might also have helped to create that niche. Engagement with local values could have brought to light possible value conflicts with users, and the opportunity to develop strategic responses.

\section{The Technological Innovator and Public Engagement}

The empirical case study illustrates the power of the public in responding to technological innovations, not through orthodox methods such as formal channels of communication and deliberation with authorities in the context of decision making processes, but via direct material engagement with the technology. Thus if dockless bicycles in Manchester/Salford is to be described as a disruptive innovation, then it was the public in responding to the innovation after implementation that contained the disruptive force, rather than the innovator and the innovation itself. Through the dynamics of the scheme development, the public indicated its response to this innovation. In direct response terms, while some users engaged through cycling, the most powerful responses were the prominent problems of theft and vandalism, which represented not only criminal behaviour, but also resistance to the scheme. At the same time, findings suggest there were also means through which the bikes could have been made more accessible to young people, who were the chief group 
responsible for the theft and vandalism. By lowering the age limit and giving them the means to pay, it was more likely that, at least over time, theft and vandalism could have been reduced.

The major decision by Mobike to reduce the geo-fencing area also indicated an inability of the company to interpret the public response. Thus, the problem of bike dispersal was seen by Mobike in terms of restricting the geo-fenced area in order to enhance commercial viability, when in reality this restricted the ability of the public to use the bikes in spatial and convenience terms. There were also problems with the bikes themselves that restricted their use in terms of safety and comfort.

The public were therefore communicating through direct mechanisms of participatory exchange, but the company failed to engage with, and thus have the option to interpret, the messages, and respond in a way that could have carried the scheme forward from being, in Christensen's (1997) terms, a 'low end disruption' to becoming a more established 'new market disruption.' It was the public that disrupted Mobike's expectations for their technological innovation, and the company lacked the means to respond in an appropriate way. If Mobike in Manchester/Salford failed to make the transition to a niche-innovation, then it was due chiefly to a failure to recognise the power of the public as end-users, and then as citizens in the wider policy context, more than their ability to shield and nurture the innovation, even though the scheme was supported by the public authorities.

The public therefore held significant power in terms of communicating responses directly, but this power was limited in terms of the innovator's reactions. In addition to its failures in taking account of public responses, Mobike was also unable to construct narratives that could allow the public to perceive the bikes in terms of a process of empowerment that could enhance mobility and choice of mode. The findings from this case centre on the power of those who won out through 'dis-use' of the scheme. It is important to note that other end users of the dockless bike share technology offered by Mobike in Manchester, such as those affected by the restrictions in the geo-fencing area, had agency, if not power, through their own direct participation. However, in this study it is not possible to assess the extent of their influence. Therefore, it could be of value in future to examine the part played by users in more successful cases of socio-technical transitions, looking at the means of participation and their effects on the construction of any niche-innovation.

As Tritter and McCallum (2005) argue, a more appropriate approach must recognise the multiple sources of potential user power, the dependence of decision makers on user support, and redraw the context within which conflict over the ability to influence decisions occurs (Tritter and McCallum, 2005, 165). Thus the typology of participation described by Arnstein (1969) is limited by its inability to recognise the need for communication through mechanisms of participatory exchange. This is very much a static and narrow interpretation of participation, and we need to understand more about its dynamics over the whole course of the policy process.

The failure of the scheme resulted chiefly from the inability of Mobike to properly prepare the ground for the scheme, then to introduce an efficient and ongoing system of research into the character of the locality, and also to construct narratives that could enhance the public image of the bikes. In essence, the company failed to work within 
any significant framework of participatory exchange, and this inability to recognise user power indicated the limitations of an innovator that relied excessively on the novelty of technological innovation. Had there been participatory creation of knowledge about such factors as identifying potential users, and the mobility needs of certain groups in the city, then the direct participation that took place could have been different. Crucially, the lack of meaningful participation in the early stages of decision making, and in the generation and shaping of knowledge, sparked a concerned public into being - a public that made its dissatisfaction with exclusion visible through ways in which the bikes got re-appropriated in a manner that defied the rules of the game as imagined by Mobike (and the councils). Consequently, the practice and skill of transport planning can be an important factor in determining project success or failure, although the dynamics of participatory exchange after implementation can place a greater premium on the creation and political management of a nicheinnovation.

In this context, the role of the public authorities was significant, but ultimately a subsidiary factor in explaining the failure as a niche-innovation. The local authorities adopted a basically non-interventionist approach to the Mobike scheme. Significant attempts were being made to develop the organisational support for cycling and its infrastructure in Greater Manchester, but this had little influence over the Mobike scheme in terms of operational regulation. However, in any circumstances this may have had limits given the lack of willingness on the part of the company to adopt a partnership approach. Institutional thickness can therefore be potentially important for the trajectory of innovations, but the Mobike Manchester/Salford case indicates the limitations when a network of co-operation and mutual dependence cannot be constructed.

The physical presence of bike share technology offers a route to power in terms of introducing a material and performed mechanism of participatory exchange, as it allows consumers to express their preferences and needs, and to do so visibly in the public realm. However, societal expectations of technological innovations are unlikely to be satisfied, such as in the case of the environmental and health benefits of cycling, if those responsible for the innovation are unwilling, or lack the means, to interpret these choices in a strategic way over time.

\section{Acknowledgements}

This paper forms part of a project: The regulation of disruptive innovations: The case of dockless bicycle hire, funded by the Rees Jeffreys Road Fund. We would like to thank the Editor and two anonymous reviewers for their valuable comments on earlier drafts of this paper.

\section{References}

Arnstein, S.R. (1969) 'A Ladder of Citizen Participation,' Journal of the American Planning Association, 35, 4, 216-224.

Boardman, C. (2017) Made to Move. Fifteen Steps to Transform Greater Manchester by Changing the Way We Get Around, Greater Manchester: Cycling and Walking Commissioner. 
Chilvers, J. (2009) 'Deliberative and Participatory Approaches in Environmental Geography,' in N. Castree, D. Demeritt, D. Liverman, and B. Rhoads (Eds) A Companion to Environmental Geography, Chichester: Wiley-Blackwell, 400-417.

Christensen, C.M. (1997) The Innovator's Dilemma, Boston, MA: Harvard Business School Press.

Christensen, C.M., Raynor, M.E. and McDonald, R. (2015) 'What is Disruptive Innovation?' Harvard Business Review, December.

Cornwall, A. (2008) 'Unpacking 'Participation': Models, Meanings, and Practices,' Community Development Journal, 43, 3, 269-83.

Dudley, G., Banister, D. and Schwanen, T. (2017) 'The Rise of Uber and Regulating the Disruptive Innovator,' The Political Quarterly, 88, 3, 492-499.

Fishman, E. (2016) 'Bikeshare: A Review of Recent Literature,' Transport Reviews, $36,1,92-113$.

Geels, F.W. (2014) 'Regime Resistance Against Low Carbon Transitions: Introducing Politics and Power into the Multi-Level Perspective,' Theory Culture and Society, 31, $5,21-40$.

Geels, F.W. (2018) 'Disruption and Low Carbon Transformation: Progress and New Challenges in Socio-Technical Transitions Research and the Multi-Level Perspective,' Energy Research \& Social Science, March, 224-231.

Geels, F.W. and Kemp, R. (2012) 'The Multi-Level Perspective as a New Perspective for Studying Socio-Technical Transitions,' in F.W. Geels, R. Kemp, G. Dudley, and G. Lyons (Eds) Automobility in Transition? A Socio-Technical Analysis of Sustainable Transport, New York: Routledge, 49-79.

Geels, F.W., Schwanen, T., Sorrell, S., Jenkins, K., and Sovacool, B.K. (2018) 'Reducing Energy Demand through Low Carbon Innovation: A Socio-Technical Transitions Perspective and Thirteen Research Debates,' Energy Research \& Social Science, 40, 23-35.

Lovell, H. (2007) 'The Governance of Innovation in Socio-Technical Systems: The Difficulties of Strategic Niche Management in Practice,' Science and Public Policy, $34,1,35-44$.

National Infrastructure Commission (2018) Urban Transport Analysis: Capacity and Cost, London: National Infrastructure Commission.

Parkes, S.D., Marsden, G., Shaheen, S.A. and Cohen, A.P. (2012) 'Understanding the Diffusion of Public Bikesharing Systems: Evidence from Europe and North America,' Journal of Transport Geography, 31, 94-103. 
Rowe, G. and Frewer, L.J. (2005) 'A Typology of Public Engagement Mechanisms,' Science, Technology and Human Values, 30, 251-290.

Royal Town Planning Institute, Planning Aid (2010) Good Practice Guide to Public Engagement in Development Schemes, London: RTPI

Schneider, H. (2017) Creative Destruction and the Sharing Economy. Uber as Disruptive Innovator, Cheltenham: Edward Elgar.

Schwanen, T. (2015) 'The Bumpy Road Toward Low-Energy Urban Mobility: Case Studies from Two UK Cities,' Sustainability, 7, 7086-7111.

Schwanen, T. (2016) 'Innovations to Transform Personal Mobility,' in D. Hopkins and J. Higham (Eds) Low Carbon Mobility Transitions, Oxford: Goodfellow Publishers.

Shaheen, S.A., Guzman, S., and Zhang, H. (2010) 'Bike Sharing in Europe, the Americas and Asia,' Transportation Research Record, 2143, 159-167.

Shaheen, S.A., Zhang, H., Martin, E., and Guzman, S. (2011) 'China's Hangzhou Public Bicycle: Understanding Early Adoption and Behavioural Response to Bikesharing,' Transportation Research Record, 2247, 1, 33-41.

Sherriff, G., Adams, M., Blazejewski, L., Davies, N, and Kamerade-Hanta, O. (2018) Bike Share in Greater Manchester, Salford: University of Salford.

Smith, A. and Raven, R. (2012) 'What is Protective Space? Reconsidering Niches in Transitions to Sustainability,' Research Policy, 41, 1025-36.

Sun, Y. (2018) 'Sharing and Riding: How the Dockless Bike Sharing Scheme in China Shapes the City,' Urban Science, 2, 68, 1-19.

Tritter, J.Q. and McCallum, A. (2006) 'The Snakes and Ladders of User Involvement: Moving Beyond Arnstein,' Health Policy, 76, 156-168.

Wilsdon, J. and Willis, R. (2004) See-Through Science. Why Public Engagement Needs to Move Upstream, London: Demos

Yi, A, Zongping, L., Mi, G., Yangpeng, Z., Daben, Y.W. and Chen, Y.J. (2018) 'A Deep Learning Approach on Short-Term Spatiotemporal Distribution Forecasting of Dockless Bike-Sharing System,' Neural Computing and Applications, 1-13.

Yin, R.K. (2003) Case Study Research: Design and Methods ( $3^{\text {rd }}$ Ed), Thousand Oaks, CA: Sage.

Zhang, Y. and Mi, Z. (2019) 'Environmental Benefits of Bike Sharing: A Big DataBased Analysis,' Applied Energy, 220, 296-301.

Figures \& Captions 
Photo 1: Mobike in Manchester

Photo 2: Vandalised Mobike in Manchester

Photo 3: Mobike in Manchester geo-fenced area November 2017. 